\title{
Physicochemical characterization, drug release and mechanical analysis of ibuprofen-loaded uhmwpe for orthopedic applications
}

\author{
Loise Silveira da Silva ${ }^{1}$ (D), Izabelle de Mello Gindri' ${ }^{1}$ (D), Gean Vitor Salmoria ${ }^{1,2 *}$ (iD) and \\ Carlos Rodrigo de Mello Roesler ${ }^{1}$
}

\begin{abstract}
${ }^{1}$ Laboratório de Engenharia Biomecânica - LEBm, Hospital Universitário, Universidade Federal de Santa Catarina - UFSC, Florianópolis, SC, Brasil

${ }^{2}$ Núcleo de Inovação em Moldagem e Manufatura Aditiva - NIMMA, Departamento de Engenharia Mecânica, Universidade Federal de Santa Catarina - UFSC, Florianópolis, SC, Brasil
\end{abstract}

*gean.salmoria@ufsc.br

\begin{abstract}
In this study, the preparation of a novel functional material for orthopedic implants using compression molding was investigated. The new functional material is envisioned to avoid inflammatory reactions in vivo after prosthesis implantation. Ibuprofen-loaded UHMWPE samples were prepared in two concentrations (3\% and 5\%) and samples were characterized in terms of physicochemical and mechanical properties. In addition, the drug-release profile was investigated. The manufacturing process resulted in a homogeneous polymer matrix with homogeneous drug dispersion. The addition of ibuprofen had a minor effect on physicochemical properties but a more significant influence on the mechanical behavior of the specimens was observed. Drug release was demonstrated and overall the results obtained showed a positive outcome with regard to the intended use. The properties analyzed remained within an acceptable range for medical application and the drug-release profile obtained for the material developed shows promise for its use as an anti-inflammatory system.
\end{abstract}

Keywords: UHMWPE, ibuprofen, biomaterial, drug delivery, orthopedic implants, material characterization.

How to cite: Silva, L. S., Gindri, I. M., Salmoria, G. V., \& Roesler, C. R. M. (2020). Physicochemical characterization, drug release and mechanical analysis of ibuprofen-loaded UHMWPE for orthopedic applications. Polimeros: Ciência e Tecnologia, 30(3), e202034. https://doi.org/10.1590/0104-1428.04220

\section{Introduction}

Total knee arthroplasty (TKA) is a standard technique used to improve mobility and reduce pain in patients with osteoarthritis, and it has been in use for the past 50 years $^{[1,2]}$. TKA is a procedure that replaces the knee joint with a set of tibial and femoral components composed of metal alloys with a polymer spacer as the articular surface ${ }^{[3]}$. Ultra-high molecular weight polyethylene (UHMWPE) has been used as the standard material to produce the insert implanted between the femoral and tibial components in TKA procedures, due to its excellent mechanical properties and biocompatibility ${ }^{[4]}$.

Despite the attractive mechanical properties of UHMWPE, which account for its use to manufacture spacers, the constant movement and contact against the tribological pair lead to wear of the polyethylene component ${ }^{[1]}$. In addition to geometrical changes associated with the wear, which may affect the performance of the implant, wear particles are generated. This wear debris is known to trigger foreign body reactions that may lead to chronic inflammation and ultimately to osteolysis, future aseptic loosening and the

need for revision surgery ${ }^{[5,6]}$, which represents a negative aspect of UHMWPE and limits the life span of the implant ${ }^{[7]}$.

When these particles are detected by the immunological system, they are phagocytosed by macrophages and multinucleated cells are formed, which lead to the activation of pro-inflammatory cytokines, such as TNF- $\alpha$, IL- $1 \beta$ and IL-6. This process results in the proliferation and maturation of osteoclasts, multinucleated cells responsible for bone resorption. On the other hand, the proliferation of osteoblasts, bone forming cells, is reduced, generating an imbalance between osteogenesis and bone resorption ${ }^{[8]}$. One approach to inhibit the development of this inflammatory reaction is the use of anti-inflammatories or bone resorption suppressors as a post-operative treatment ${ }^{[9]}$.

Recent studies have demonstrated the 10-year implant survival rate for TKR was $96.1 \%$, and the 20 -year implant survival rate was $89 \cdot 7 \%$. However, for younger and more active patients the lifetime risk of revision increased up to $35 \%$ with great differences between female and male patients $(15 \% \text { lower for women in same age group })^{[10]}$. Although TKA has high success rates, with more than a million procedures 
conducted every year ${ }^{[9]}$, problems related to inflammatory reactions, such as osteolysis, are one of the main factors linked to the high number of revision surgerie ${ }^{[11]}$. According to AJRR (American Joint Replacement Registry) ${ }^{[12]}$, in 2016, 3.4\% of all knee replacement procedures performed in the United States were revision surgeries, and $13 \%$ of these were related to inflammatory reactions surrounding the implant area.

Various alternatives related to the manufacturing process and material composition have been tested over the past few years to maintain the positive aspects of this material and, at the same time, improve its relationship with the human body and the wear properties. Crosslinked-UHMWPE has emerged as a promising material for total hip arthroplasty with some improved properties when compared with conventional UHMWPE. However, in TKA, this material has not demonstrated the same benefits. This is due to the multidirectional cyclic movements of the knee combined with a reduction in the mechanical properties and fatigue resistance observed for crosslinked-UHMWPE ${ }^{[13]}$. Thus, conventional UHMWPE has shown better performance in TKA procedures and remains, along with Vitamin E-loaded UHMWPE, the preferred choice of material.

UHMWPE with the antioxidant Vitamin E incorporated was developed as an alternative to reduce the oxidative reaction that occurs during in vivo use. In the material matrix this antioxidant reacts with free radicals and retards the oxidative process ${ }^{[14]}$. UHMWPE with Vitamin E has been used in arthroplasty procedures and has shown positive results in terms of wear resistance and particle interaction with the immunological system ${ }^{[4]}$.

In order to reduce the number of revision procedures by reducing inflammatory reactions and infections, researchers all around the world have been testing the incorporation of different drugs, such as vancomycin ${ }^{[15]}$, gentamicin ${ }^{[5]}$, bupivacaine $^{[16]}$ and bisphosphonates ${ }^{[17]}$, to avoid infection and inhibit bone resorption. Although there have been some good outcomes, this kind of technology is still in the pre-clinical testing phase as it deals with humans, and therefore has not yet been used in arthroplasty procedures.

Considering the constant need to improve the performance of UHMWPE in TKA, this paper proposes the formulation of a novel biomaterial based on the incorporation of ibuprofen (IBU) into the UHMWPE polymeric matrix. IBU has been used as a post-operative treatment in arthroplasty procedures, as a treatment for local pain and inflammations associated with arthritis and musculoskeletal problems ${ }^{[18]}$ and incorporated in different polymers to reach and treat specific areas of the human body ${ }^{[19]}$. The IBU-loaded UHMWPE prepared in this study is aimed at reducing the inflammatory reaction after implantation, which would help to reduce the number of revision surgeries caused by periprosthetic loosening due to osteolysis. IBU-UHMWPE specimens were prepared by compression molding and then characterized in terms of their physicochemical properties, drug release profile and mechanical properties. The results and data obtained were used to discuss the potential of the material developed, to analyze the effect of IBU on the physicochemical and mechanical properties, and to investigate the drug-release profile.

\section{Experimental}

\subsection{Materials}

UHMWPE resin (GUR 1020, Ticona) was the main material used to prepare the specimens, along with IBU (Viafarma, Joinville, Brazil). As a way to compare the material properties and behavior, specimens with drug concentrations of $3 \mathrm{wt} \%$ and $5 \mathrm{wt} \%$ were prepared as well as specimens without the addition of the anti-inflammatory drug. The specimens were named UHMWPE, UHMWPE 3\% IBU and UHMWPE $5 \%$ IBU.

\subsection{Preparation of specimens}

Specimens were prepared according to the methodology proposed by Suhardi et al. ${ }^{[15]}$ with some modifications. The compression molding process was carried out in a hydraulic press with a load capacity of 15 tons (Bonevau, Rio do Sul, Brazil). Samples of UHMWPE 3\% IBU (0.3 g IBU: $9.7 \mathrm{~g}$ of UHMWOE) and UHMWPE $5 \%$ IBU (0.5 g IBU: $9.5 \mathrm{~g}$ of UHMWPE) were previously prepared by mixing the polymer and the drug for $10 \mathrm{~min}$. Each formulation was placed in the mold and kept at $150^{\circ} \mathrm{C}$ and $5 \mathrm{MPa}$ for $15 \mathrm{~min}$ to reach total material consolidation. After this period, the specimens were cooled to room temperature. All test specimens were prepared according to standard specifications as will be detailed in the following sections.

\subsection{Specimen characterization}

\subsubsection{Physicochemical analysis}

Differential scanning calorimetry (DSC) was conducted on all specimens to determine the thermal parameters, such as melting point temperature $\left(T_{m}\right)$, melting enthalpy and the degree of crystallinity according to ASTM F2625-10. Three specimens, with masses of between $0.003 \mathrm{~g}$ and $0.008 \mathrm{~g}$, were extracted from each formulation proposed and sealed in an appropriate aluminum pan for posterior analysis in DSC equipment (PerkinElmer 600, São Paulo, Brazil). Tests were run with a heating/cooling rate of $10{ }^{\circ} \mathrm{C} / \mathrm{min}$ and the crystallinity degree was obtained by integration of the endotherm peak between $50^{\circ} \mathrm{C}$ and $160^{\circ} \mathrm{C}$. Thin films were prepared for Fourier-transform infrared spectroscopy and microscopy experiments. The films were obtained from different regions of specimens to address the material uniformity. Specimens of $1 \mathrm{~cm} \mathrm{x} 1 \mathrm{~cm} \times 1 \mathrm{~cm}$ were removed from each specimen and embedded in paraffin. Slices of $200 \mu \mathrm{m}$ and $90 \mu \mathrm{m}$ were obtained from paraffin embedded specimens with the aid of a microtome for Fourier infrared (FTIR) spectroscopy and microscopy analysis, respectively. The FTIR spectroscopy was performed in the transmission mode and according to ASTM 2102-13. Optical microscopy (Nikon E-200) was performed to evaluate the quality of the consolidation process. The films were evaluated under $100 \mathrm{X}$ magnification. Lastly, density measurements of three specimens of each formulation were taken following Archimedes' principle. The specimens were prepared with at least $1 \mathrm{~mm}$ of thickness for each $1 \mathrm{~g}$ of material with a maximum of $5 \mathrm{~g}$, as recommended by the technical standard ASTM D792-13. 


\subsubsection{Drug release test}

Spectrophotometric analysis was conducted using a UV-Vis spectrophotometer (Model UV-5200, Global Trade Technology, Monte Alto, Brazil) to obtain the release profile and investigate the way in which the drug would be eluted from the UHMWPE when implanted in the human body. IBU, in concentrations of $(\mathrm{mg} / \mathrm{ml}) 0.0652$, $0.125,0.25,0.5,1.0,2.0,2.5,3.0$ and 4.0 , was dissolved in phosphate buffer solution (PBS, $\mathrm{pH}=7.4$ ) and then analyzed in the spectrophotometer at a wavelength $\left(\lambda_{\max }\right)$ of $264 \mathrm{~nm}$ to prepare the IBU calibration curve (Figure S1, Supporting Information, Supplementary Material). The UHMWPE specimens with IBU were then immersed in $3 \mathrm{~mL}$ of PBS and placed in a Dubnoff bath at a temperature of $37.0 \pm 0.5^{\circ} \mathrm{C}$. The entire PBS volume was collected from each specimen after $6 \mathrm{~h}$ and $24 \mathrm{~h}$, then every $24 \mathrm{~h}$ for one week and subsequently twice a week until the $30^{\text {th }}$ day of the drug release test (Figure S2). After each PBS collection, the amount taken for the test was replaced with fresh PBS. Due to the nature of the system developed, the models chosen to analyze the data were the zero-order model, Higuchi model and Korsmeyer-Peppas model (also known as the power law model) ${ }^{[20]}$. The curves resulting from this analysis are provided in Figures S3 - S5.

\subsubsection{Mechanical testing}

Mechanical testing was performed according to technical standard ASTM D638 with some modifications. These experiments were carried out on a universal testing machine (DL 3000, EMIC, São José dos Pinhais, Brazil) operating with a load cell of $500 \mathrm{~N}$ and at a test speed of $1 \mathrm{~mm} / \mathrm{min}$, with the use of an Instron extensometer (Cat. No. 2630-107, Instron, Norwood, USA) with a gauge length of $25 \mathrm{~mm}$ and travel length of $+25 /-2.5 \mathrm{~mm}$. The length between grips during the tests was $33.9 \mathrm{~mm}$. Three specimens of each drug concentration were machined into a dumbbell-shaped format, $2 \mathrm{~mm}$ thick and with a cross-section area of $6 \mathrm{~mm}^{2}$, to obtain the elastic modulus and tensile yield strength of the specimens for posterior analysis of the effect of the IBU on the mechanical properties. The elastic modulus specimens were obtained in the linear strain region of 0.0005 to $0.0025 \mathrm{~mm} / \mathrm{mm}$.

\section{Results and Discussion}

\subsection{Physicochemical analysis}

The consolidation process was investigated using optical microscopy. Images obtained for UHMWPE, UHMWPE 3\% IBU and UHMWPE 5\% IBU are shown in Figure 1. Figure 1a shows a UHMWPE specimen, on which only cut marks are observed, indicating a satisfactory consolidation procedure. The presence of the drug in the polymeric matrix is confirmed for both UHMWPE 3\% IBU and UHMWPE 5\% IBU, as demonstrated in Figures $1 \mathrm{~b}$ and 1c, respectively, in which IBU crystals can be observed.

The DSC and density results are summarized in Table 1. The data demonstrate that the addition of IBU did not affect the melting point temperature, onset temperature, crystallinity percentage and polymer density $(p>0.05)$. The reference density values for medical grade UHMWPE are in the range of $927-944 \mathrm{~kg} / \mathrm{m}^{3[21]}$. Also, according to the literature, crystallinity values should be between 50 and $55 \%{ }^{[4]}$ and the melting point temperature in the range of $125-138^{\circ} \mathrm{C}^{[22]}$. The results of our analysis exhibit a positive outcome, showing values in agreement with the reference data provided in the literature and in the technical standard specification ASTM F648 regarding UHMWPE for medical applications ${ }^{[21]}$.

The material composition was confirmed through FTIR analysis. A spectrum for each composition is shown in Figure 2, along with the IBU spectrum to locate and compare the IBU peaks in the UHMWPE 3\% IBU and UHMWPE 5\% IBU specimens.

The IBU, UHMWPE, UHMWPE 3\% IBU and UHMWPE 5\% IBU spectra are shown in Figures 2a-d. The peak at around $1720 \mathrm{~cm}^{-1}$ in the IBU, UHMWPE $3 \%$ IBU and UHMWPE 5\% IBU spectra corresponds to the carbonyl group present in the drug composition. The detection of this peak in the UHMWPE 3\% IBU and UHMWPE 5\% IBU specimens confirms the incorporation of the drug in the polymeric matrix. Characteristics of the UHMWPE bands include: symmetric and asymmetric stretching of $\mathrm{C}-\mathrm{H}$ in the $\mathrm{CH}_{2}$ groups located at $2950 \mathrm{~cm}^{-1}$ and $2850 \mathrm{~cm}^{-1}$, respectively; and vibration bands in the range of $1350 \mathrm{~cm}^{-1}$ and $1450 \mathrm{~cm}^{-1}$
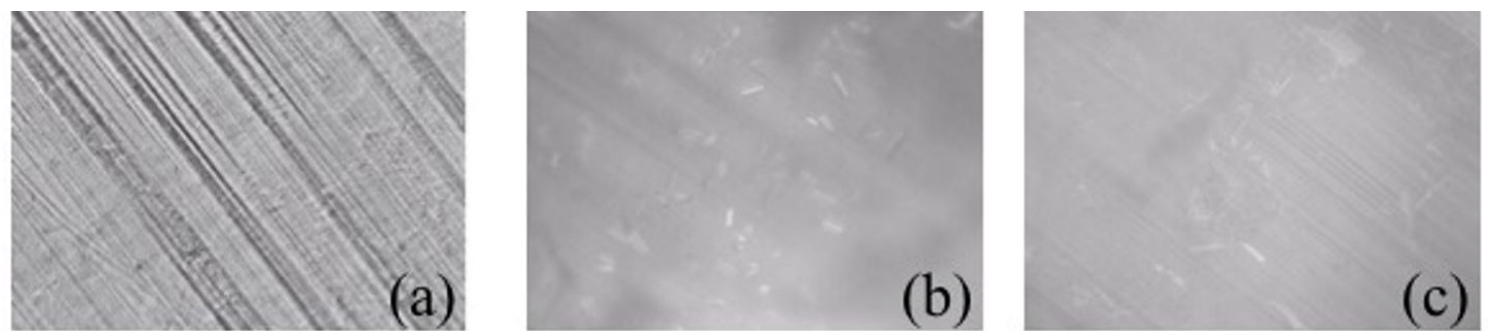

Figure 1. Microscopic images taken with a magnification of 200X: (a) UHMWPE, (b) UHMWPE 3\% IBU and (c) UHMWPE $5 \%$ IBU.

Table 1. Physicochemical properties.

\begin{tabular}{ccccc}
\hline & $\mathbf{T}_{\mathbf{m}}\left[{ }^{\circ} \mathbf{C}\right]$ & $\mathbf{T}_{\text {onset }}\left[{ }^{\circ} \mathbf{C}\right]$ & $\mathbf{X}_{\mathbf{c}}[\mathbf{\%}]$ & $\mathbf{D e n s i t y ~}\left[\mathbf{k g} / \mathbf{m}^{3}\right]$ \\
\hline UHMWPE & $131.94 \pm 0.98$ & $122.47 \pm 0.94$ & $53.12 \pm 1.70$ & $927.30 \pm 3.70$ \\
UHMWPE 3\% IBU & $131.02 \pm 0.55$ & $122.34 \pm 0.32$ & $53.69 \pm 3.97$ & $930.43 \pm 7.22$ \\
UHMWPE 5\% IBU & $131.06 \pm 0.50$ & $121.72 \pm 0.27$ & $52.58 \pm 0.37$ & $928.28 \pm 3.48$ \\
\hline
\end{tabular}




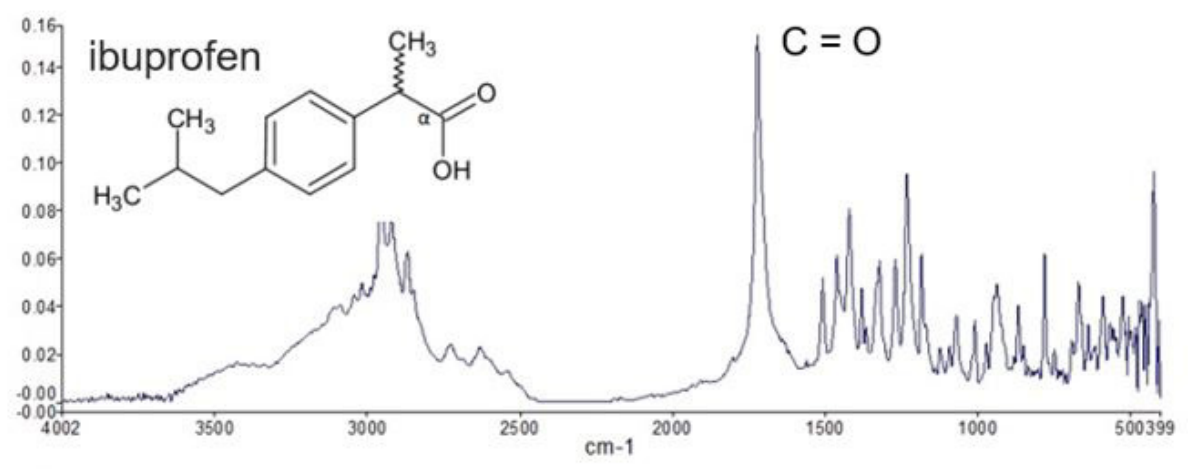

(a)

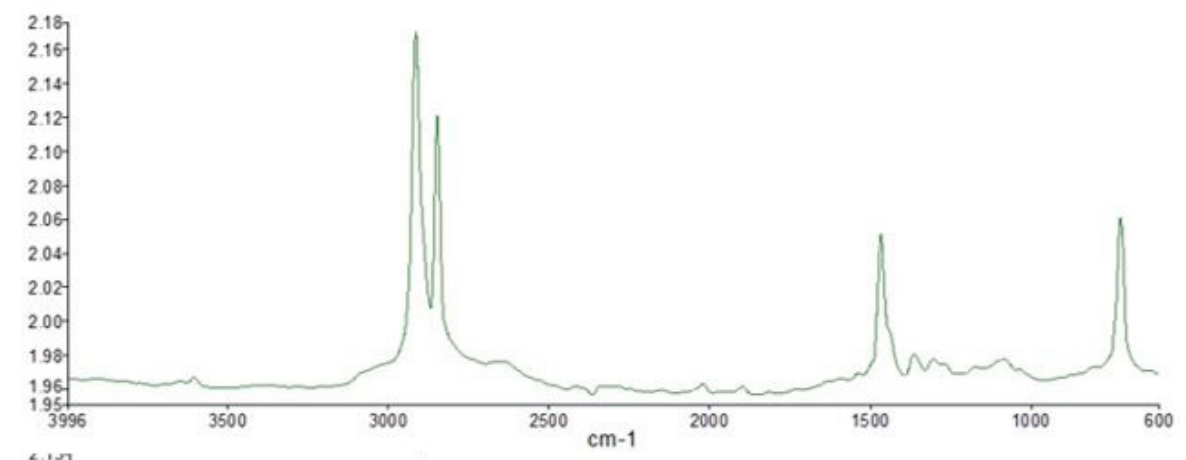

(b)

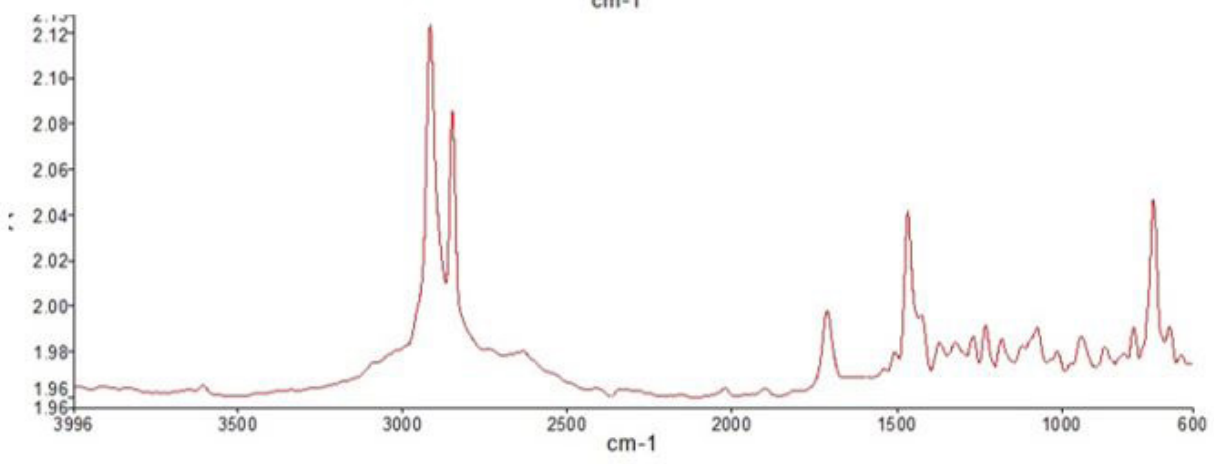

(c)

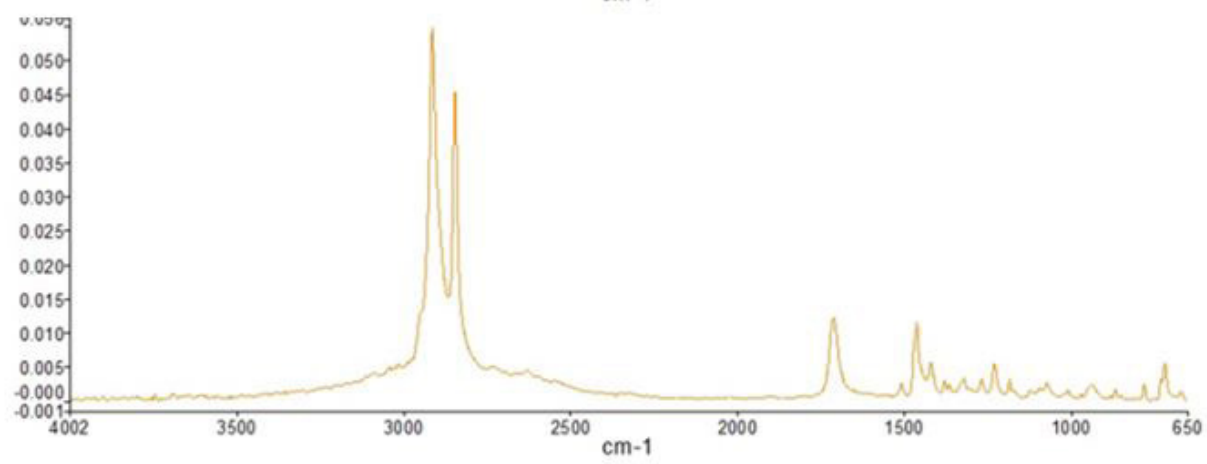

(d)

Figure 2. FTIR spectra for (a) IBU, (b) UHMWPE, (c) UHMWPE 3\% IBU and (d) UHMWPE 5\% IBU.

associated with the $\mathrm{CH}_{2}$ bending movement and at $720 \mathrm{~cm}^{-1}$ with the $\mathrm{CH}_{2}$ rocking vibration. For the IBU, bands between $3300 \mathrm{~cm}^{-1}$ and $2500 \mathrm{~cm}^{-1}$ correspond to the stretching of $\mathrm{OH}$ in the carboxylic acid groups and the vibration of $\mathrm{C}-\mathrm{H}$ in $\mathrm{CH}_{3}$ and in the phenyl functional groups. As previously mentioned, a characteristic band of IBU, with a high intensity, is located at $1720 \mathrm{~cm}^{-1}$ representing the stretching of the carbonyl bond $\mathrm{C}=\mathrm{O}^{[23]}$.

\subsection{Drug release test}

The two UHMWPE formulations with IBU are classified as a possible drug-release system by diffusion, where the drug is eluted from the polymeric matrix over a prolonged time frame. The data obtained from the drug release tests were analyzed by mathematical methods developed from the First Law of Fick ${ }^{[24,25]}$. The IBU calibration curve used to analyze 
the data obtained by spectrophotometry analysis is shown in Figure S1 in the Supporting Information. The coefficients used to calculate the amount of IBU released at each interval of analysis were extracted from this curve, leading to the total amount released by the system at the end of the test. The results obtained over the 30-day period of IBU release are shown in Figure 3 (\%) and Figure S2 ( $\mathrm{mg} / \mathrm{ml})$.

The results for the percentage of drug released show that of the total drug theoretically incorporated in the specimens, UHMWPE 3\% IBU eluted approximately $7.8 \%$ and UHMWPE 5\% IBU released $9.7 \%$ within the first 7 days of the tests. The UHMWPE 3\% IBU specimen released $1.59 \mathrm{mg}$ in the first week while UHMWPE 5\% IBU released $2.90 \mathrm{mg} / \mathrm{ml}$. In the second week, around $12.00 \%$ of the total was eluted from UHMWPE 3\% IBU and 14.79\% from UHMWPE 5\% IBU, representing $2.26 \mathrm{mg}$ and $4.42 \mathrm{mg}$, respectively. After 30 days, UHMWPE 3\% IBU had released $3.81 \mathrm{mg}$ and UHMWPE 5\% IBU $7.05 \mathrm{mg}$, representing $19.62 \%$ and $23.91 \%$, respectively. These data demonstrate that the IBU release is more accentuated at the beginning of the eluting period, followed by a more controlled and smooth release over time. The total amounts theoretically incorporated in each specimen were $20.39 \mathrm{mg}$ for UHMWPE 3\% IBU and $29.95 \mathrm{mg}$ for UHMWPE 5\% IBU.

The kinetic release profiles (Figure S3-S5) for the materials developed showed that the data for the UHMWPE 5\% IBU specimen best fitted the Higuchi's Model (with a correlation coefficient of 0.9942), while for the UHMWPE 3\% IBU specimen the best fit was obtained with the Korsmeyer-Peppas model (with a correlation factor of 0.9949). Although the UHMWPE 3\% IBU release coefficient indicated a non-Fickian diffusion release $\mathrm{e}^{[24,25]}$, with a release exponent of 0.6091, the correlation coefficient obtained with Higuchi's Model was also higher than 0.99 , which suggests that the UHMWPE 3\% IBU release may also be governed by Fickian diffusion. An overview of the results obtained from the kinetic analysis is given in Table 2.
The kinetic release coefficients obtained for the Higuchi model confirm that the IBU release is governed by diffusion, with values of less than 0.5 , indicating transport governed by Fick's Law ${ }^{[20,24]}$. In addition, considering Higuchi's Model, the kinetic release coefficient of UHMWPE 3\% IBU was 0.013 , which is smaller than the value for UHMWPE $5 \%$ IBU of 0.015 . Therefore, the higher concentration of IBU in the polymer seems to facilitate the diffusion of the drug, as a greater portion of it may be in contact with the polymer matrix.

The application of mathematical models indicated that the UHMWPE/IBU formulation as a system is governed by Higuchi's Model, especially the formulation with the higher IBU concentration. This suggests that at the higher concentration a greater portion of the anti-inflammatory is in contact with the matrix, which would facilitate its diffusion process. The results demonstrate a gradual drug release over time, which is of interest for polymeric systems intended for anti-inflammatory applications ${ }^{[23]}$, such as the prevention of osteolysis. Furthermore, the drug release occurred over a longer period compared with other systems, such as bupivacaine ${ }^{[16]}$, vancomycin ${ }^{[15]}$ and gentamicin-loaded $\mathrm{UHMWPE}^{[5]}$, in which antibiotic elution occurred over 5, 12 and 25 days, respectively. While antibiotic systems are designed to achieve release in short periods after implantation to avoid infections, an anti-inflammatory is expected to act for a longer period, to mitigate capsular formation after implantation as well as osteolysis due to particle generation.

\subsection{Mechanical testing}

The tensile curves obtained from the tests are shown in Figures $4 \mathrm{a}, 4 \mathrm{~b}$ and $4 \mathrm{c}$ for UHMWPE, UHMWPE 3\% IBU and UHMWPE 5\% IBU, respectively. The three formulations tested showed similar mechanical behavior and the error between specimens within the same group was small. The differences between the material compositions demonstrate a decrease in their elastic modulus $(\mathrm{p}<0.05)$, as expected

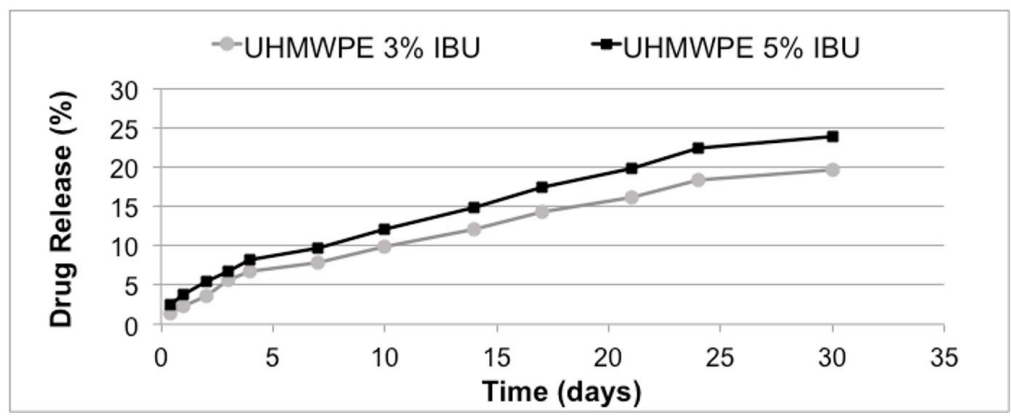

Figure 3. Drug release in percentage (\%) over a 30-day period.

Table 2. Kinetic analysis results.

\begin{tabular}{ccccccc}
\hline SPECIMEN & \multicolumn{3}{c}{ UHMWPE 3\% IBU } & \multicolumn{3}{c}{ UHMWPE 5\% IBU } \\
\hline KINETIC MODEL & $\mathrm{K}$ & $\mathrm{r}$ & $\mathrm{K}$ & $\mathrm{r}$ & \\
ZERO-ORDER MODEL & 0.002 & 0.989 & & 0.003 & 0.992 & \\
HIGUCHI MODEL & 0.013 & 0.994 & & 0.015 & 0.994 & $\mathrm{n}$ \\
& $\mathrm{K}$ & $\mathrm{r}$ & $\mathrm{n}$ & $\mathrm{K}$ & $\mathrm{r}$ & 0.530 \\
\hline
\end{tabular}

$\mathrm{K}=$ release kinetic coefficient; $\mathrm{r}=$ correlation coefficient; $\mathrm{n}=$ release exponent 

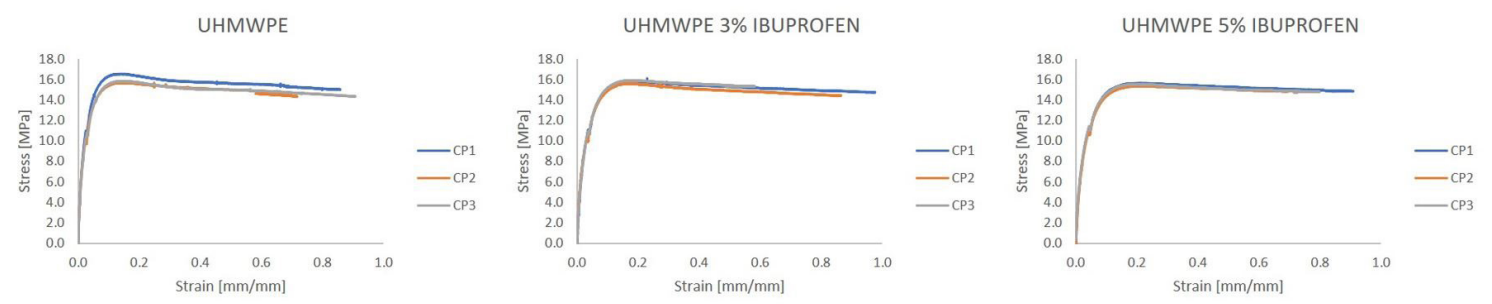

Figure 4. Engineering stress - strain curves obtained from tensile tests $(\mathrm{CP}=$ specimen $)$.
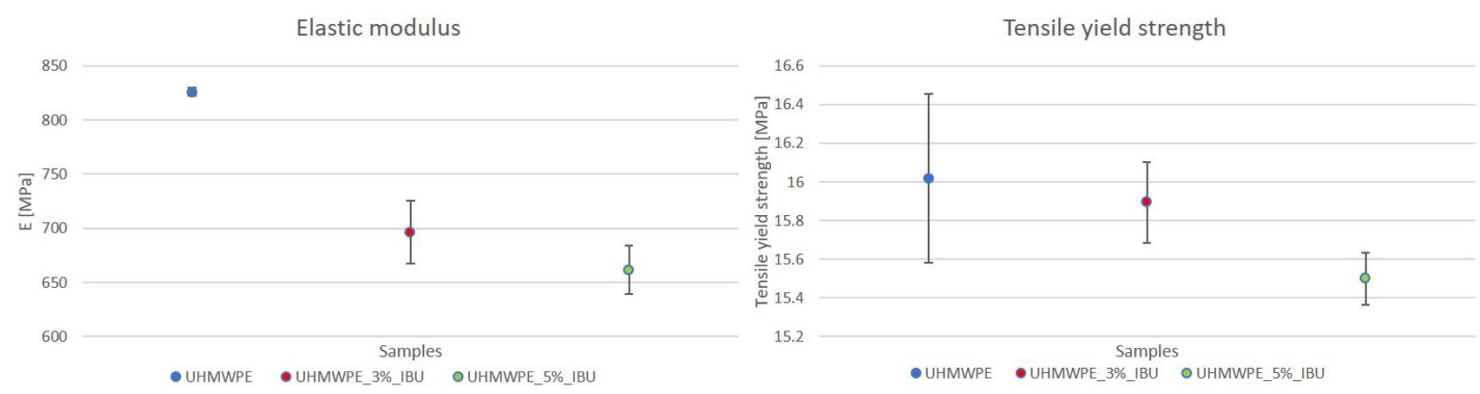

Figure 5. Comparison of elastic modulus and tensile yield strength results for the different formulations tested.

Table 3. Elastic modulus and tensile yield strength results.

\begin{tabular}{ccc}
\hline & E [MPa] & $\begin{array}{c}\text { Tensile yield strength } \\
\text { [MPa] }\end{array}$ \\
\hline UHMWPE & $825.89 \pm 3.62$ & $16.02 \pm 0.44$ \\
UHMWPE 3\% IBU & $696.12 \pm 28.92$ & $15.89 \pm 0.21$ \\
UHMWPE 5\% IBU & $661.45 \pm 22.61$ & $15.50 \pm 0.14$ \\
\hline
\end{tabular}

with the addition of a doping agent in the polymeric matrix. Results are summarized in Table 3.

The results in Table 3 and Figure 5 indicate that the addition of $3 \%$ of IBU to the polymeric matrix decreased the elastic modulus by $16 \%$. However, despite this decrease, the value remained between $500 \mathrm{MPa}$ and $800 \mathrm{MPa}$, that is, within the range recommended for the use of UHWMPE as a biomaterial[ ${ }^{[22]}$. The $5 \%$ formulation provided a similar result, with a decrease of up to $20 \%$ in relation to the UHMWPE without the drug. These results suggest that the addition of IBU facilitates the molecular chain mobility and increases the ductility of the material.

No significant difference was noted for the tensile yield strength when comparing UHMWPE, UHMWPE 3\% IBU and UHMWPE 5\% IBU ( $>0.05)$, which means that the addition of the drug did not have a notable impact on this parameter. The same behavior has been observed for alendronate and vancomicyn-loaded UHMWPE, with drug contents of less than or equal to $5 \%$.

\section{Conclusions}

The results reported herein demonstrate the incorporation of IBU, an anti-inflammatory drug, into UHMWPE for the first time. The consolidation process selected produced specimens with a homogeneous matrix, total polymer fusion and a good IBU dispersion, as demonstrated by the microscopy analysis. The addition of IBU resulted in minor effects on the crystallinity, melting point temperature, onset temperature and density. The drug release experiments demonstrated controlled and sustained drug release. Specimens with higher drug content resulted in greater percentages of release. The mechanical tests showed the influence of IBU on the mechanical properties of UHMWPE. The modulus of elasticity values for the two IBU formulations ( 0.0005 and $0.0025 \mathrm{~mm} / \mathrm{mm}$ ) were up to $20 \%$ lower when compared with the UHMWPE without the drug. Despite the impact on the mechanical properties, the results obtained were satisfactory, demonstrating that the addition of IBU had only a slight impact on the quasi-static mechanical properties of the UHMWPE. The wear behavior and cyclic load effects need to be evaluated in future work. Overall, the specimens of UHMWPE with IBU incorporated showed positive results with regard to their use in arthroplasty procedures. The characteristics and properties are consistent with those recommended for biomedical applications and the release profiles are promising for an anti-inflammatory system. Further tests and improvements must be carried out to achieve a better combination of parameters and obtain a raw material suitable for knee implants, aimed at reducing the number of inflammatory reactions and, consequently, the number of revision surgeries.

\section{Acknowledgements}

The authors would like to thank Coordenação de Aperfeiçoamento de Pessoal de Nível Superior CAPES (I.M.G and L.S.S), and Conselho Nacional de Desenvolvimento Científico e Tecnológico - CNPq (G.V.S and C.R.M.R) for financial support.

\section{References}

1. Kurtz, S. M., \& Kurtz, S. M. (2004). Chapter 8-The clinical performance of UHMWPE in knee replacements. In S. M. 
Kurtz (Ed.), The UHMWPE handbook: ultra-high molecular weight polyethylene in total joint replacement (pp. 151-188). Cambridge: Academic Press. https://doi.org/10.1016/B978012429851-4/50009-7.

2. Kurtz, S. M., \& Kurtz, S. M. (2004). Chapter 7 - The origins and adaptations of UHMWPE for knee replacements. In S. M. Kurtz (Ed.), The UHMWPE handbook: ultra-high molecular weight polyethylene in total joint replacement (pp. 123-150). Cambridge: Academic Press. https://doi.org/10.1016/B978012429851-4/50008-5.

3. Carr, B. C., \& Goswami, T. (2009). Knee implants - review of models and biomechanics. Materials \& Design, 30(2), 398-413. http://dx.doi.org/10.1016/j.matdes.2008.03.032.

4. Bracco, P., Bellare, A., Bistolfi, A., \& Affatato, S. (2017). Ultra-high molecular weight polyethylene: influence of the chemical, physical and mechanical properties on the wear behavior. A Review. Materials (Basel), 10(7), 791. http:// dx.doi.org/10.3390/ma10070791. PMid:28773153.

5. Manoj Kumar, R., Gupta, P., Sharma, S. K., Mittal,A., Shekhar, M., Kumar, V., Manoj Kumar, B. V., Roy, P., \& Lahiri, D. (2017). Sustained drug release from surface modified UHMWPE for acetabular cup lining in total hip implant. Materials Science and Engineering C, 77, 649-661. http://dx.doi.org/10.1016/j. msec.2017.03.221. PMid:28532076.

6. Nabeshima, A., Pajarinen, J., Lin, T., Jiang, X., Gibon, E., Córdova, L. A., Loi, F., Lu, L., Jämsen, E., Egashira, K., Yang, F., Yao, Z., \& Goodman, S. B. (2017). Mutant CCL2 protein coating mitigates wear particle-induced bone loss in a murine continuous polyethylene infusion model. Biomaterials, 117, 1-9. http://dx.doi.org/10.1016/j.biomaterials.2016.11.039. PMid:27918885.

7. Topolovec, M., Cör, A., \& Milošev, I. (2014). Metal-on-metal vs. metal-on-polyethylene total hip arthroplasty tribological evaluation of retrieved components and periprosthetic tissue. Journal of the Mechanical Behavior of Biomedical Materials, 34,243-252. http://dx.doi.org/10.1016/j.jmbbm.2014.02.018. PMid:24608233.

8. Steinbeck, M. J., \& Veruva, S. Y. (2016). Pathophysiologic reactions to UHMWPE wear particles. In In S. M. Kurtz (Ed.), UHMWPE biomaterials handbook ultra high molecular weight polyethylene in total joint replacement and medical devices (pp. 506-530). USA: Elsevier. http://dx.doi.org/10.1016/B978-0323-35401-1.00028-4

9. Purdue, P. E., Koulouvaris, P., Potter, H. G., Nestor, B. J., \& Sculco, T. P. (2007). The cellular and molecular biology of periprosthetic osteolysis. Clinical Orthopaedics and Related Research, 454, 251-261. http://dx.doi.org/10.1097/01. blo.0000238813.95035.1b. PMid:16980902.

10. Bayliss, L. E., Culliford, D., Monk, A. P., Glyn-Jones, S., PrietoAlhambra, D., Judge, A., Cooper, C., Carr, A. J., Arden, N. K., Beard, D. J., \& Price, A. J. (2017). The effect of patient age at intervention on risk of implant revision after total replacement of the hip or knee: a population-based cohort study. Lancet, 389(10077), 1424-1430. http://dx.doi.org/10.1016/S01406736(17)30059-4. PMid:28209371.

11. Huang, Y.-F., Zhang, Z.-C., Xu, J.-Z., Xu, L., Zhong, G.-J., He, B.-X., \& Li, Z.-M. (2016). Simultaneously improving wear resistance and mechanical performance of ultrahigh molecular weight polyethylene via cross-linking and structural manipulation. Polymer, 90, 222-231. http://dx.doi.org/10.1016/j. polymer.2016.03.011.

12. Berry, D. J., Bozic, K. J., \& Lewallen, D. G. (2016). AJRR Annual Report 2016 (pp. 46). Rosemont, IL: American Academy of Orthopaedic Surgeons (AAOS).

13. Pruitt, L. A. (2005). Deformation, yielding, fracture and fatigue behavior of conventional and highly cross-linked ultra high molecular weight polyethylene. Biomaterials, 26(8), $905-$ 915. http://dx.doi.org/10.1016/j.biomaterials.2004.03.022. PMid: 15353202.

14. Wernle, J. D., Mimnaugh, K. D., Rufner, A. S., Popoola, O. O., Argenson, J.-N., \& Kelly, M. (2017). Grafted vitamin-E UHMWPE may increase the durability of posterior stabilized and constrained condylar total knee replacements. Journal of Biomedical Materials Research. Part B, Applied Biomaterials, 105(7), 1789-1798. http://dx.doi.org/10.1002/jbm.b.33710. PMid:27192378.

15. Suhardi, V. J., Bichara, D. A., Kwok, S., Freiberg, A. A., Rubash, H., Malchau, H., Yun, S. H., Muratoglu, O. K., \& Oral, E. (2017). A fully functional drug-eluting joint implant. Nature Biomedical Engineering, 1(6), 1-21. http://dx.doi.org/10.1038/ s41551-017-0080. PMid:29354321.

16. Gil, D., Grindy, S., Muratoglu, O., Bedair, H., \& Oral, E. (2019). Antimicrobial effect of anesthetic-eluting ultra-high molecular weight polyethylene for post-arthroplasty antibacterial prophylaxis. Journal of Orthopaedic Research, 37(4), 981-990. http://dx.doi.org/10.1002/jor.24243. PMid:30737817.

17. Yang, D., Qu, S., Huang, J., Cai, Z., \& Zhou, Z. (2012). Characterization of alendronate sodium-loaded UHMWPE for anti-osteolysis in orthopedic applications. Materials Science and Engineering C, 32(2), 83-91. http://dx.doi.org/10.1016/j. msec.2011.09.012.

18. Celebi, D., Guy, R. H., Edler, K. J., \& Scott, J. L. (2016). Ibuprofen delivery into and through the skin from novel oxidized cellulose-based gels and conventional topical formulations. International Journal of Pharmaceutics, 514(1), 238-243. http:// dx.doi.org/10.1016/j.ijpharm.2016.09.028. PMid:27863667.

19. Salmoria, G. V., Paggi, R. A., Castro, F., Roesler, C. R. M., Moterle, D., \& Kanis, L. A. (2016). Development of PCL/ ibuprofen tubes for peripheral nerve regeneration. Procedia CIRP, 49, 193-198. http://dx.doi.org/10.1016/j.procir.2015.11.014.

20. Klauss P. (2010). Desenvolvimento de dispositivos poliméricos implantáveis para a liberação de fármaco fabricados por sinterização seletiva a laser [Tese de doutorado]. Programa de Pós-graduação em Ciência e Engenharia dos Materiais, Centro Tecnológico, Universidade Federal de Santa Catarina, Florianópolis.

21. ASTM International. (1980). F648-80: standard specification for ultra-high-molecular-weight polyethylene powder and fabricated form for surgical implants. West Conshohocken: ASTM International.

22. Kurtz, S. M. (2004). The UHMWPE handbook: ultra-high molecular weight polyethylene in total joint replacement. Cambridge: Academic Press.

23. Vieira, E. S., Salmoria, G. V., de Mello Gindri, I., \& Kanis, L. A. (2018). Preparation of ibuprofen-loaded HDPE tubular devices for application as urinary catheters. Journal of Applied Polymer Science, 135(2), 1-8. http://dx.doi.org/10.1002/ app. 45661 .

24. Manadas, R., Pina, M. E., \& Veiga, F. (2002). A dissolução in vitro na previsão da absorção oral de fármacos em formas farmacêuticas de liberação modificada. Revista Brasileira de Ciência do Solo, 38(4). http://dx.doi.org/10.1590/S151693322002000400002.

25. Costa, P. J. C. (2002). Avaliação in vitro da lioequivalência de formulações farmacêuticas. Revista Brasileira de Ciências Farmacêuticas, 38(2), 141-153. http://dx.doi.org/10.1590/ S1516-93322002000200003.

Received: May 09, 2020

Revised: Sept. 15, 2020

Accepted: Oct. 12, 2020 


\section{Supplementary Material}

Supplementary material accompanies this paper.

Figure S1. IBU calibration curve.

Figure S2.Drug release in $\mathrm{mg}$ /day in 30 days.

Figure S3. Zero order model fit.

Figure S4. Higushi model fit.

Figure S5. Korsmeyer-peppas model fit.

This material is available as part of the online article from http://www.scielo.br/polimeros 